\title{
"Depois aconteça o que acontecer": por uma rediscussão do Caso Panther e da política externa de Rio Branco
}

\author{
"Then come what may": for a rediscussion on the Panther \\ Affair and on Rio Branco's foreign policy
}

RENATO AMADO PEIXOTO*

Rev. Bras. Polít. Int. 54 (1): 44-66 [2011]

O suposto rapto de um alemão residente em Itajaí (SC) por um navio de guerra alemão, no ano de 1905, converteu-se num incidente diplomático de grande repercussão no Brasil, na Alemanha e nos Estados Unidos ficando conhecido como o "Caso Panther". Mais de sessenta anos depois, o Caso Panther foi redescoberto pelos historiadores e trabalhado a partir de diferentes aproximaçôes, que imprimiam então sua marca na própria política externa nacional.

Nosso objetivo, neste trabalho, é esclarecer esse debate, entendendo que o conhecimento puro e simples da historiografia não nos assegura a compreensão e o sentido do passado: é preciso que esta historiografia, transformada em história, torne-se também objeto de interrogação e investigação. Somente a partir dessa compreensão é possível que novos elementos sejam incorporados ao exercício da interpretação, possibilitando outras aproximaçōes que não apenas aquelas consolidadas no cânone de uma "cultura histórica" (GUIMARÃES, 2005). No caso da história da política externa, tal exercício torna-se ainda mais sensível, na medida em que as relações com uma cultura histórica estão mais diretamente ligadas à disputa por memórias que em outros lugares da disciplina. Na história da política externa, essas disputas implicam diretamente o balanço das relações de força nos loci de produção de ideias, de operação da política e de reelaboração do saber diplomático.

Por conseguinte, para reproblematizar o Caso Panther, torna-se necessário desnaturalizar a escrita de sua historiografia, entendendo que, nesse exercício, o historiador compartilhou experiências, foi o receptor de tradições e contextualizou ideias. No caso, devemos considerar ainda o envolvimento do historiador, no sentido amplo que essa noção pode ter, ou seja, de que o autor pode ser simultaneamente sujeito passivo e ativo de uma ou mais operaçôes.

\footnotetext{
* Renato Amado Peixoto é professor adjunto da Universidade Federal do Rio Grande do Norte (UFRN), onde atua no Departamento de História e no Programa de Pós-Graduação em História (PPGH).
} 


\section{A historiografia e o Caso Panther: Burns e a "aliança não escrita"}

Embora tenha tido grande repercussão no Brasil, nos Estados Unidos e na Alemanha em seu tempo, conforme veremos no decorrer do artigo, e tenha sido apontado em 1912 nos Atos Diplomáticos do Brasil por José Manoel Cardoso de Oliveira (1997, 335-336), o Caso Panther não mereceu maior atenção dos historiadores, nem dos biógrafos de Rio Branco, à exceção de Álvaro de Barros Lins, até a metade da década de 1960. Mesmo Luiz Viana Filho apenas menciona $\mathrm{o}$ incidente em duas breves passagens sobre as perspectivas da carreira política de Rio Branco (1959, 363 e 368).

Portanto, deve-se a Álvaro Lins a constituição dos enunciados fundamentais a partir dos quais se desdobraram as sucessivas leituras do episódio: a atuação da imprensa; o clamor popular motivado pelo medo do "perigo alemão"; a repercussão internacional do incidente; o desmentido da intervenção estadunidense; a declaração de Rio Branco de que o Brasil iria à guerra contra a Alemanha, se necessário fosse, retirada por Lins do diário do próprio Ministro.

Observe-se que, depois disso, o episódio foi apenas alinhavado brevemente por Pedro Calmon no sexto volume de sua História do Brasil (1959, 2010), e depois apontado fora de seu contexto por Hélio Vianna em sua História Diplomática do Brasil, como um exemplo do contumaz desrespeito alemão às normas do direito internacional, característica da atuação daquele país no sistema internacional até a Segunda Guerra Mundial (VIANNA, 1958, 189). Fora essas notas, o Caso Panther não foi citado sequer nos manuais de política externa da época, como, por exemplo, a História Diplomática do Brasil de Carlos Delgado de Carvalho (1959).

Somente com a publicação do livro The Unwritten Alliance: Rio-Branco and Brazilian-American Relations de Edward Bradford Burns o Caso Panther ganharia maior importância para a historiografia, servindo nessa obra como elemento de articulação para a hipótese de que Rio Branco foi o responsável pela virada da política externa brasileira em direção aos Estados Unidos. Procuraremos estabelecer brevemente certos traços inerentes a essa escritura.

Burns, então professor assistente da Universidade da Califórnia, havia passado aproximadamente um ano no Brasil pesquisando em várias instituições e arquivos particulares do País, munido de cartas de recomendação que facilitaram muito seu acesso a estes. The unwritten alliance foi lançado em 1966 com o apoio da Ford Foundation pelo Institute of Latin American Studies, entidade que havia sido estabelecida pela Universidade de Columbia em resposta a uma "necessidade nacional, pública e educacional por um melhor entendimento dos problemas contemporâneos das nações da América Latina" e de modo a ampliar as bases de conhecimento para as relações dos Estados Unidos com esses países $(1966, v)$.

Por conseguinte, há que se vincular, em primeiro lugar, o esforço de Burns a todo um contexto latino-americano do final da década de 1950, informado pela Revolução Cubana e pelo esforço estadunidense em circunscrever, senão 
conter, os seus reflexos. Os pesquisadores que se dispunham a seguir para esse ambiente desafiador eram, por excelência, observadores privilegiados do momento histórico, homens sensíveis à conexão de seu trabalho com os esforços do governo estadunidense. Em segundo lugar, outro contexto, o brasileiro, deve ser considerado. O período em que Burns pesquisa e escreve seu livro foi marcado pelo golpe de 1964 e, mais especificamente, pelos esforços de política externa do governo Castelo Branco. Se formos salientar as principais características desses esforços, cabe-nos notar a sincronia entre a diplomacia do Brasil e a dos Estados Unidos, que cuidavam então de reformular a Carta da Organização dos Estados Americanos (OEA) e de organizar uma Força Interamericana de Paz permanente (FIP) sob o comando brasileiro. Essas iniciativas demonstravam o alinhamento de interesses entre os dois países, iniciativas que visavam constituir uma hegemonia regional que interessava ao fortalecimento da posição hemisférica estadunidense. A pretensão de hegemonia regional brasileira seria claramente formulada em direção ao Uruguai, ao Paraguai e à Bolívia, países para os quais diversas iniciativas de integração comercial, cultural e militar foram combinadas por cálculo estratégico que se baseava nas ideias formuladas desde a década de 1950 na Escola Superior de Guerra (ESG). Esse posicionamento era facilitado internamente por uma audiência de diplomatas, militares e civis suscetível a um saber e a um discurso geopolítico que permitiu, desde o final dos anos 1940, a reunião dos interesses e esforços das corporações militar e diplomática, que integrou paulatinamente as agendas da Escola de Comando e Estado-Maior do Exército (ECEME) e do Instituto Rio Branco (PEIXOTO, 2000). Em terceiro lugar, deve-se considerar a hipótese de Burns no contexto do grande embate de ideias acerca da política externa brasileira que se desenvolveu desde as décadas de 1940-1950.

Burns trabalha a ideia de que a historicidade da "amizade tradicional" entre os Estados Unidos e o Brasil deveria ser perscrutada apenas a partir da República, já que o exame das relações diplomáticas entre os dois países no século XIX não permitiria outra leitura (1966, Preface). Nessa lógica, Rio Branco havia trabalhado desde sua posse para acelerar a aproximação e "alinhar, o mais proximamente possível, o Brasil com os Estados Unidos", porque havia percebido "desde a ultima década do século XIX”, que esse alinhamento viabilizaria certos objetivos da política externa do Brasil. Segundo Burns, Rio Branco operou inicialmente de modo a eliminar os atritos pendentes entre os dois países, para depois poder convencer o Departamento de Estado que os objetivos brasileiros convergiam com os da Doutrina Monroe, e que aquele país podia contar com sua colaboração para defender a Doutrina na América do Sul (1966, 200-201). Assim, por meio dos esforços de Rio Branco, constituir-se-ia uma "aliança não escrita" em que o Brasil apoiaria os objetivos da política externa estadunidense no hemisfério, como, por exemplo, a independência do Panamá, enquanto os Estados Unidos apoiariam as iniciativas brasileiras, como a expansão de suas fronteiras. 
Para Burns, "a aliança serviu mais ao Brasil que aos Estados Unidos”, uma vez que "o Barão usou os Estados Unidos" não apenas para "expandir os limites brasileiros", mas também "para escapar da dominação britânica” e para ampliar sua liderança e prestígio (BURNS, 1966, 204-205). Nesse raciocínio, depois de terminada a etapa de expansão das fronteiras, os Estados Unidos teriam passado a apoiar a luta do Brasil pela obtenção de prestígio e liderança regional, e mais: como o Brasil havia reconhecido a influência estadunidense no Caribe, os Estados Unidos reconheceram, em contrapartida, "a esfera de influência brasileira, Uruguai, Paraguai e Bolívia” (1966, 207-208).

$\mathrm{Na}$ interpretação de Burns, o Caso Panther permitia sintetizar o momento preciso a partir do qual as desconfianças entre os dois países se dissiparam, demonstrando as vantagens de uma "amizade próxima" com os Estados Unidos. Nesse sentido, o incidente teria aumentado o apreço pela Doutrina Monroe no Brasil, uma vez que a solidariedade estadunidense abria novas possibilidades na política externa e demonstrava que a aproximação podia gerar ganhos para nossas posições. Ainda, a solução do incidente demonstrava a maestria da diplomacia brasileira - no caso, "esta diplomacia, a doutrina Monroe e a amizade brasileiroamericana emergiram como vitoriosos no Caso Panther" (1966, 201).

Por meio da conjunção de circunstâncias operada pelo incidente da Panther, pôde-se mesmo ressignificar a visita do Secretário de Estado Elihu Root ao Rio de Janeiro para a Terceira Conferência Pan-americana. Como esta acontecia no âmbito do recrudescimento do confronto entre as posiçōes argentinas e estadunidenses em torno da Doutrina Drago, e no momento mesmo em que as relações do Brasil com a Argentina tinham se deteriorado a um ponto limite, a visita significou a "prova tangível da estima dos Estados Unidos em relação ao Brasil” (1966, 107), e a consubstanciação da "aliança não escrita" tanto no plano regional como no hemisférico.

A narrativa do incidente constitui-se claramente em diálogo com a descrição de Álvaro Lins, procurando reconstruir o papel de Joaquim Nabuco, o embaixador brasileiro em Washington de 1905 a 1910, no suposto pedido de intervenção estadunidense. Ao contrário de Lins, Burns não relata a indignação de Rio Branco com a notícia, mas louva a eficiência de Nabuco, considerando que sua atuação possibilitou que o Caso Panther fosse muito divulgado nos jornais dos Estados Unidos (1966, 104-105). Além disso, Joaquim Nabuco seria o responsável direto pela vinda de Elihu Root ao Brasil, já que suas estreitas ligações de amizade com o Secretário de Estado seriam determinantes para o sucesso do convite. Ao final, Burns divide mesmo entre Rio Branco e Nabuco o crédito pela "aliança”, já que esta somente sucedeu porque "dois extraordinários homens de estado [...] trabalharam juntos rumo ao objetivo comum da amizade brasileiro-americana” (1966, 203).

A narrativa de Lins fechava-se em torno da figura de Rio Branco, buscando denotar o caráter patriótico de sua atuação no Ministério. Nesse intuito, salientavase a contrariedade de Rio Branco com a notícia do pedido de intervenção 
estadunidense: "o Brasil resolveria sozinho o incidente que dizia respeito à sua soberania e honra nacional". Ainda, Lins valeu-se do efeito de expressōes como "a desproporção de forças entre o Brasil e a Alemanha", "o frêmito nacional" para produzir um crescendo dramático que esclareceria a posição de Rio Branco na famosa cena do encontro com o embaixador alemão: "Pois que seja uma guerra, Excelência, se isto desgraçadamente for necessário” (1965, 345-347).

Buscando evitar contradições entre a sua interpretação e a de Álvaro Lins, Burns não se refere ao encontro e, ao transcrever a ordem de Rio Branco que originou o contato entre Joaquim Nabuco e o Departamento de Estado, omite sua parte final, deixando de transcrever: "Vou reclamar entrega preso condenação se formal ato. Se inatendidos empregaremos force libertar preso ou meteremos a pique Panther. Depois aconteça o que acontecer...” (1966, 104).

Essas elisões permitem não apenas aventar a intenção por detrás da construção de Burns, mas também explicitar o contexto que envolve o diálogo entre os dois autores, no caso, o embate de ideias acerca da política externa brasileira na década de 1960. Entendemos que, para adequar a narrativa de Lins à sua construção, Burns tem de retirar algo que deseja elidir em sua própria construção, afinal, Burns elimina elementos que permitiriam melhor contextualizar o incidente em seu tempo, porque isso lhe permite elidir um tema (a intervenção) e instruir uma fala (a de Joaquim Nabuco) que faz parte do contexto da sua própria escrita. Afinal, vivia-se em 1966 uma fratura profunda em nossa sociedade quando se criticava o alinhamento com os Estados Unidos, contestava-se o regime instituído no Brasil graças à ajuda desse país, e combatia-se o mesmo Governo que, em 1966, agraciou Burns com a Ordem de Rio Branco.

\section{José Honório Rodrigues e o "americanismo de Rio Branco"}

Devemos notar que a construção de Burns se vale de diversas contribuições e estabelece diálogos que ainda hoje talvez não estejam bem compreendidos. Observe-se que o próprio Burns deixa claro, logo no início de seu livro, que Hélio Viana, Luiz Viana Filho e Maurício Nabuco foram leitores dos originais e também os responsáveis por comentar capítulos específicos. Além disso, Burns também relata que manteve diversos encontros com José Honório Rodrigues, muito provavelmente em 1964, quando este era diretor do Arquivo Nacional (1966, xii).

No mesmo ano em que Burns lança The unwritten alliance, José Honório Rodrigues publica Interesse nacional e política externa com o objetivo, segundo a apresentação de Maria Yedda Leite Linhares, de debater o "alinhamento do Brasil ao ocidentalismo norte-americano e suas implicações mundiais, por via de um estranho e novo conceito de segurança nacional". A obra de Rodrigues colocavase, portanto, na oposição ao regime instituído e à sua política externa, "na luta entre o Brasil arcaico e o Brasil novo que quer nascer e está nascendo" e visava combater a "submissão a interesses políticos exóticos" que marcavam a política 
da interdependência com os Estados Unidos, a "ideologia do suicídio nacional” (1966, 3 e 7).

Comparando a estrutura narrativa dos livros de Burns e de Rodrigues, podemos interpretar que o debate de ideias acerca da política externa que então se processava no Itamaraty e na sociedade brasileira encontrou em Burns e Rodrigues os seus dois intérpretes privilegiados. Inicialmente, podemos perceber que Interesse nacional e política externa também procura constituir um sentido da ligação entre Estados Unidos e Brasil por meio da descrição e análise de sua história. No caso, Rodrigues entende, tal como Burns, que a aproximação com os Estados Unidos e a consequente "deseuropeização de nossa política externa" foram obras de Rio Branco e constituíram orientação diferente daquela experimentada pela política externa do Império. Para Rodrigues $(1966,102)$, o chamado "americanismo" de Rio Branco significava a adoção de uma "marcha de acordo, se possível," com os Estados Unidos e "atendia a objetivos transitórios e não permanentes", visando "fazer frente às manobras hostis" dos argentinos. Assim, se uma aliança com os Estados Unidos fizera parte dos cálculos dos estadistas do Império, estes a entendiam de outro modo, a saber, no mesmo quadro da relação com as potências mais fortes, como parte de uma estratégia geral que procurava não comprometer a política do país e seus interesses, e que evitava que compromissos com aquelas potências se traduzissem na tutela sobre o Brasil.

Depois, Rodrigues procura explicitar a própria ambivalência das intenções estadunidenses em relação ao Brasil durante o século XIX, frisando que, em várias ocasiōes, esse país exerceu pressões que não foram menores que as exercidas pela Grã-Bretanha, o que demonstrava o acerto do princípio da política externa do Império. Por conseguinte, as relações com os Estados Unidos durante o Império atendiam mais ao objetivo de procurar um melhor equilíbrio nas disputas do Brasil com os países hispano-americanos.

Finalmente, para Rodrigues $(1966,106)$, seria com a intervenção armada estadunidense durante o governo Floriano Peixoto (1891-1894) que o Brasil passaria do "neutralismo [...] para uma linha de aceitação passiva da preponderância" daquele país. Contudo, a diretriz política de Rio Branco não deveria ser confundida com essa política nem com o alinhamento que caracterizou a política externa do Brasil depois de sua morte, denominado por Rodrigues de "linha de conformação", a partir da qual o Brasil deixou de ser entendido como um país singular, sendo incorporado a um conjunto de nações sobre o qual passou a incidir uma hegemonia "tão civilizadora e tão colonial, quanto exerciam os Poderes Europeus na África e na Ásia”.

Note-se que José Honório Rodrigues, assim como Burns, escrevia para uma audiência semelhante; daí, por exemplo, o emprego de termos como "interesses não permanentes" que faziam parte do jargão da ESG, bem como a utilização de enunciados como "posição de equilíbrio", que faziam parte do saber geopolítico. A narrativa de Rodrigues buscava sensibilizar as corporaçôes diplomática e militar, 
utilizando o argumento nacionalista para investir nas fraturas então existentes. Nesse sentido, Interesse nacional e politica externa, apontava sobretudo o "Bacharelismo e o Complexo de Caiação", a saber, o predomínio das elites tradicionais no Itamaraty e, por conta disso, de seus interesses e ideias, divorciados da sociedade brasileira, como os responsáveis pela tutela estadunidense.

$\mathrm{Na}$ construção de Rodrigues (1966, 46-65), Rio Branco representava justamente a antítese do "bacharelismo" e a busca de uma sincronia com a nação, por conta da execução de uma política externa que visava o incremento das possibilidades de desenvolvimento do país. Assim, mesmo a delimitação das fronteiras, topos comum nas construções da personagem Rio Branco, foi reelaborada por Rodrigues (1966, 25): "esta tarefa [...] não foi só obra do Barão do Rio Branco [...] não foi só obra de um regime ou de partidos; pertence à Nação [...]". Tornava-se impossível para a narrativa de Rodrigues que Rio Branco pudesse, sequer indiretamente, ter alguma participação no suposto pedido de intervenção, trabalhado nos livros de Burns e Lins.

O problema da audiência é fundamental para compreender porque Burns e Rodrigues tinham ambos que dialogar com o Rio-Branco de Álvaro Lins, obra já então parte do cânone do Instituto Rio Branco e, mais especificamente, com a ideia de que a política de aproximação com os Estados Unidos promovida por Rio Branco não era original, mas uma solução de continuidade em relação à política do Império: "uma moldura nova e brilhante para dar relevo a um quadro antigo" $(1965,329)$.

\section{Álvaro Lins e a rearticulação do topos da continuidade}

No caso, a chave de leitura do problema é que Álvaro Lins fundamentou sua ideia sobre o recurso retórico da autoridade, utilizando diretamente um texto atribuído a Rio Branco, O Brasil, os Estados Unidos e o Monroísmo. Esse texto teria sido publicado sob o pseudônimo de J. Penn em 12 de maio de 1906 no Jornal do Commercio, e visava responder às críticas feitas então à política de aproximação com os Estados Unidos "por alguns raros publicistas brasileiros que se supóem genuínos intérpretes e propagadores do pensamento político dos estadistas do Império", fazendo saber, por meio da citação à mensagem de Rodrigues Alves ao Parlamento em 3 de maio de 1906, que a política de aproximação fora expressamente autorizada pela Presidência:

Tenho grande satisfação em ver que cada vez mais se estreitam as relações de cordial amizade entre o Brasil e os Estados Unidos da América. Concorrendo para isso, não tenho feito mais do que seguir a política traçada desde 1822 pelos fundadores da nossa Independência e invariavelmente observada por todos os Governos que o Brasil têm tido (RIO BRANCO, 1943, 170). 
Buscando seguir o tom da mensagem de Rodrigues Alves e visando uma audiência específica, Rio Branco elaborou um relato da aproximação que a fazia remontar ao período anterior à Independência, desenvolvendo, em seguida, o raciocínio de que esta fora estimulada pela necessidade de resistir-se à ameaça das potências europeias e às intrigas dos países hispano-americanos. Após a morte de Rio Branco, O Brasil, os Estados Unidos e o Monroísmo passaria a ser citado fora do contexto imediato e republicado com indicação da autoria de Rio Branco, justificando quaisquer políticas e iniciativas de alinhamento com os Estados, e seria nesse sentido que Rio Branco inauguraria o topos da continuidade da aproximação com os Estados Unidos na historiografia da política externa brasileira. Contudo, é necessário compreender que o texto de Rio Branco foi escrito no contexto determinado pelo Caso Panther para responder às críticas feitas então à projetada visita de Elihu Root ao Rio de Janeiro. No artigo, Rio Branco cuidou de encadear a visita de Elihu Root num elenco de atitudes e iniciativas que teriam se iniciado antes da Independência, permitindo defendê-la por meio de sua remissão a uma historicidade inquestionável. Isso pode ser facilmente depreendido se cuidarmos de verificar o texto da mensagem presidencial de Rodrigues Alves, já que nesta se faz uma recapitulação dos acontecidos em 1905; ademais, se notarmos que a citação empregada por Rio Branco em seu texto foi recortada do trecho da "mensagem" que anuncia a visita de Elihu Root:

A 25 de julho espera chegar a capital, em visita ao Brasil, o secretário de Estado dos Estados Unidos da América, S. Elihu Root, que será nosso hóspede durante alguns dias.

Tenho grande satisfação em ver que cada vez mais se estreitam as relações de cordial amizade entre o Brasil e os Estados Unidos da América. Concorrendo para isso, não tenho feito mais do que seguir a política traçada desde 1822 pelos fundadores da nossa Independência e invariavelmente observada por todos os Governos que o Brasil tem tido.

$\mathrm{Na}$ verdade, Álvaro Lins rearticulou o topos da continuidade por meio de sua própria narrativa da política externa de Rio Branco, construindo a ideia de que o ministro teria sempre planejado e operado de modo que a aproximação se tornasse ainda mais palpável. Note-se que a narrativa de Álvaro Lins insere anacronicamente o artigo de Rio Branco na narrativa, uma vez que este é citado em seguimento a uma descrição das negociações sobre o Acre. Isso lhe permite a operação do raciocínio de que "nunca o Barão apelaria, nunca apelou, para o expediente de um pedido de intervenção parcial dos Estados Unidos [...]", e juntar nesse raciocínio o episódio da elevação das representaçôes dos dois países à categoria de embaixada, cujo fechamento seria a célebre frase: "Era como que uma moldura nova e brilhante para dar relevo a um quadro antigo". Observe-se que Álvaro Lins não data a citação ao artigo de Rio Branco, mas apenas menciona 
que este fora "publicado no Jornal do Commercio e muitas vezes reproduzido em outros jornais e folhetos" (1965, 329, nota 556).

Por conseguinte, a frase "moldura nova e brilhante para dar relevo a um quadro antigo", tantas vezes citada, é a representação da reelaboração do topos da continuidade feita por Álvaro Lins, com o qual nem Burns nem Rodrigues concordavam: para Burns a "aliança não escrita" deveria ser compreendida apenas no contexto da República e dos ministérios Rio Branco; para Rodrigues, o "americanismo" de Rio Branco deveria ser entendido como circunstância lógica, mas transitória de um processo. No diálogo com Lins, Burns constitui o Caso Panther como elemento de ligação da narrativa que lhe permite interpretar o alinhamento do Brasil com os Estados Unidos, ao mesmo tempo em que eleva Joaquim Nabuco como personagem principal da trama que culmina na vinda de Elihu Root ao Rio de Janeiro. Já para Rodrigues, se confiarmos nas apostilas do curso de História Diplomática que lecionou no Instituto Rio Branco e que foram reunidas por Ricardo Seitenfus, só cabia citar o incidente da Panther para demonstrar que Rio Branco concebia as "relações tão estreitas quanto possível, mas sem que isso pudesse prejudicar nossa liberdade de ação soberana" (RODRIGUES, 1995, 67-68). Por conta disso o incidente é completamente marginal nas obras de Rodrigues, sendo apenas mencionado para que se pudesse frisar que Rio Branco fez questão de desmentir os jornais na questão do apelo de intervenção aos Estados Unidos.

No sentido de melhor compreensão do nosso problema, podemos agora colocar que duas aproximações historiográficas principais podem ser delineadas a partir do debate colocado em 1966: a primeira entendendo o alinhamento com os Estados Unidos como uma consequência da política encetada por Rio Branco; a segunda desvinculando Rio Branco da prática dos seus sucessores, a adesão ao "imperialismo protetor" dos Estados Unidos.

\section{O Caso Panther depois de Burns e Rodrigues}

Em 1972, Luiz Alberto de Vianna Moniz Bandeira revisitaria o Caso Panther e seu contexto. No livro Presença dos Estados Unidos no Brasil, Moniz Bandeira insere o incidente numa interpretação do contexto histórico em que salienta os "colossais interesses dos construtores de navios" que buscavam lucrar com o acirramento dos sentimentos imperialistas. Nesse sentido, Moniz Bandeira salienta que a imprensa estadunidense veiculava continuamente denúncias de que a Alemanha pretendia "apoderar-se de território na América do Sul" e que a frequência dessas notícias, segundo o próprio representante brasileiro em Washington, era a prova de sua intencionalidade $(1978,167)$. Contudo, Moniz Bandeira entende que a disputa imperialista não era de todo infundada e os Estados Unidos estavam entrando em uma nova fase de sua política externa, "emergindo para o Imperialismo", dinâmica esta confirmada pelo acerto feito com as grandes potências europeias na Crise da 
Venezuela em 1902, na secessão do Panamá em 1903, e na invasão da República Dominicana em 1905.

Por conseguinte, Moniz Bandeira interpreta que o apoio de Rio Branco à Doutrina Monroe se deu em função do entendimento de que esta resguardaria o Brasil contra as agressóes extracontinentais e permitiria constituir "uma associação com os Estados Unidos, em pé de igualdade", visando tanto "a transformação do Continente numa espécie de condomínio em que o Brasil ficava com as mãos livres para exercer a sua hegemonia na América do Sul" quanto o alívio das pressōes que a Inglaterra exercia $(1978,169-170)$.

Podemos observar, assim, que o problema do imperialismo estadunidense colocado pela análise de Rodrigues foi reconsiderado por Moniz Bandeira a partir de sua remissão ao contexto internacional, enquanto as intenções de Rio Branco no processo de aproximação com aquele país foram explicadas no âmbito hemisférico por meio do topos da continuidade da política externa brasileira: "era, no fundo, a velha orientação do Império, que adquiria consciência e forma” (1978, 169). Podemos compreender ainda a explicação de Moniz Bandeira pela influência do contexto da ditadura militar brasileira (1964-1985) em sua escrita, pois esse autor coloca, ainda que sub-repticiamente, uma explicação para outra continuidade, a do pleito da sub-hegemonia continental, um dos focos da política externa desde o governo Castelo Branco.

Restava, entretanto, uma tensão a ser resolvida na narrativa: se considerarmos que Moniz Bandeira foi influenciado por Rodrigues, como explicar, sem se afastar demasiadamente da narrativa anterior, que as intenções de Rio Branco não consubstanciaram uma tentação de alinhamento com os Estados Unidos? Para isso, Moniz Bandeira lança mão exatamente da interpretação concorrente, reelaborando o papel construído por Burns para o personagem de Joaquim Nabuco. Mantendo o protagonismo de Nabuco na narrativa da aproximação e na cena do incidente da Panther, Moniz Bandeira constrói uma personagem antagônica à de Rio Branco. No caso, o embaixador brasileiro em Washington não teria compreendido "o sentido que Rio Branco imprimia ao Monroísmo", dando-lhe "o sentido da adulação aos Estados Unidos", e, citando Oliveira Lima, Moniz Bandeira indicou que "sua atitude foi, invariavelmente, pan-americana do Norte", pois "julgava um bem o Brasil ser dirigido pelos Estados Unidos" (1978, 171).

Essa reelaboração do papel de Joaquim Nabuco seria então juntada ao argumento nacionalista que Rodrigues havia elaborado na figura retórica do "Bacharelismo". Vários enunciados acerca de Joaquim Nabuco são então disponibilizados de modo a constituir um par semântico com a figura do "Bacharel" constituída por Rodrigues e exemplificada na frase: "a vaidade, o amor próprio e não sei se o interesse daqueles que nos governam e que querem brilhantes e vantajosas sinecuras no exterior [...]" (RODRIGUES, 1966, 51). Observe-se a seguinte citação: 
Nabuco envaidecia-se de seu trabalho. E de seu charme. O de mais belo homem de Washington. Convenceu-se de que impressionou Root a ponto de induzi-lo a viajar ao Rio de Janeiro. E de que sua escolha marcava uma época [...] Estas e outras lisonjas, com que o Presidente Theodore Roosevelt contemplava o seu narcisismo, ele consignou no seu diário. E procurou pagá-las com a vassalagem [...] (BANDEIRA, 1978, 173).

$\mathrm{Na}$ construção de Moniz Bandeira, as manobras de Joaquim Nabuco foram contidas apenas pela firmeza com que Rio Branco visava seus objetivos, mas, descrevendo por Joaquim Nabuco a essência dos diplomatas brasileiros, a morte de Rio Branco permitia encadear quase que naturalmente um processo. No caso, o incidente da Panther excitara, ao extremo, a "solidariedade e comunhão de sentimentos, que os representantes das oligarquias formulavam sob a regência de Root", pois, ao final, "Lauro Müller substituiu-o no Ministério das Relações Exteriores e, logo, manifestou seu espírito de subserviência" (1978, 173 e 187).

Esse viés seria retomado em 1988 por José Joffily no seu livro O Caso Panther, mas, no tratamento dispensado por esse autor, nem mesmo Rio Branco se salvaria, sendo caracterizado como um indivíduo intempestivo e excêntrico, e equiparado a Joaquim Nabuco pela "beleza apolínea, o culto a certos hábitos lúdicos". Nessa construção, Joffily, citando Aníbal Fernandes, lembra, inclusive, "que Nabuco tinha fama de 'dandy' ou 'correur de femme'. Chegaram a inventar que usava pulseirinhas de ouro e que punha brilhantina nos bigodes" (1988, 106). Igualando as duas personagens na narrativa, Joffily podia revelar a pusilanimidade de nossas elites e utilizar o Caso Panther como uma representação da condição do colonizado. O incidente servia para revelar "as raízes da nossa carga de colonialismo e de rendição incondicional ao imperialismo que corre nas veias da burguesia brasileira e de suas elites" $(1988,43)$. Escrevendo no estertor do período de exceção, Joffily criticava o ensino de história e a própria historiografia, acusando esta pela canonização da classe dirigente. Assim, o argumento central do autor é que no incidente da Panther a má condução da política externa do País por Rio Branco e Joaquim Nabuco quase teriam levado o Brasil a uma guerra contra a Alemanha, mas que tais circunstâncias e o próprio incidente foram deixados de lado pelos historiadores, censurados no movimento de autoindulgência de nossas elites. Ironicamente, Joffily reifica em sua narrativa o argumento que o próprio imperialismo estadunidense utilizou para lastrear suas pretensōes no início do século XX, o chamado "Perigo alemão", o expansionismo germânico em direção ao Brasil.

Depois de Joffily, curiosamente, parte da historiografia subscreve ao mesmo tempo as teses de Burns e de Rodrigues, não compreendendo mais haver distinção entre as ideias da "aliança não escrita" e do "americanismo" de Rio Branco. Contudo, de um modo geral, a construção de Rodrigues prevaleceu sobre as outras, na medida em que, mesmo considerando a importância de Joaquim Nabuco na narrativa da aproximação com os Estados Unidos, a maioria dos autores entende 
haver uma separação entre seu papel e o de Rio Branco na questão. No caso, a aproximação com os Estados Unidos seria descrita enquanto parte de uma estratégia de Rio Branco que visava neutralizar as intervençôes que poderiam ser perpetradas contra o Brasil, servindo aos propósitos do País sem que significasse alienação da soberania, entendimento este que iria adquirir outro significado, o do alinhamento, após a morte de Rio Branco (CERVO, 1992, 174). Em praticamente todas as obras sobre a política externa brasileira, o incidente da Panther desapareceria enquanto elemento articulador da narrativa, sendo apenas citado esporadicamente de modo a endossar o direcionamento de certas explicaçōes pontuais. ${ }^{1}$

A exceção à regra é o artigo de Clodoaldo Bueno intitulado $A$ competição alemã no Brasil no início do século: o incidente da Panther, escrito em 1995, trabalho em que esse autor busca, a partir do incidente, entender as linhas básicas da ação de Rio Branco em meio à disputa entre Estados Unidos e Alemanha. O interessante é que, embora a abordagem de Bueno seja original (a tese do "meio ambiente" como condicionador da ação de Rio Branco), a interpretação do autor subscreve os vieses abertos por Burns e Rodrigues, como se pode depreender do título com que Bueno nomeia a conclusão do artigo: "Reforço da presença norte-americana e do prestígio de Rio Branco". No caso, os temas principais das teses de Burns e Rodrigues foram agrupados e reelaborados numa só composição.

Finalmente, nos últimos anos, como parte dos esforços dedicados a reavaliar a memória de Joaquim Nabuco, alguns trabalhos têm se dedicado a salientar mais o papel desempenhado por este na aproximação com os Estados Unidos e se valem, nessa operação, do incidente da Panther. Esta foi, por exemplo, a análise desenvolvida por Rubens Ricúpero na conferência apresentada ao Seminário Joaquim Nabuco, Embaixador do Brasil em 2005.

\section{A rediscussão do Caso Panther por meio da crítica à cultura histórica}

Pudemos observar em nossa análise da historiografia sobre o Caso Panther que o incidente ganhou relevância a partir de um contexto determinado - a ditadura militar -, quando passou a ser operado em duas operações historiográficas para as quais assumiria distintos valores de representação. Essas representações seriam reelaboradas até que desaparecesse o interesse em torno da própria operação, quando os valores trabalhados foram subsumidos na grade geral de compreensão da política externa brasileira.

Entretanto, mesmo que desligados de sua origem e de suas representações, os sentidos de compreensão operados na historiografia (especialmente os que dizem respeito ao papel da corporação diplomática e ao relacionamento com os Estados

1 Por exemplo, como elemento que possibilitou a compreensão estrangeira acerca do posicionamento brasileiro em relação à Doutrina Monroe, ver Cervo (1992, 166); como elemento dinamizador do rearmamento brasileiro, ver Doratioto $(2000,137)$; e como parte do argumento que sustentava a compreensão de uma ligação mais estreita entre Brasil e Alemanha, ver Bandeira $(1994,31)$. 
Unidos) foram reelaborados e rearticulados em outros enunciados por novas operações realizadas na disputa por posições no interior do sistema que articula a ação diplomática com o pensamento da política externa. Essa análise permite explicar por que a maioria dos novos elementos acerca do incidente da Panther foi incorporada a outras investigações em vez de se juntar a sua interpretação, assim como as interpretaçóes mais recentes se desligaram dos sentidos do debate e até confundiram as suas ideias.

Uma retomada da análise do Caso Panther por meio dos termos das operaçōes e de avaliação de seus desdobramentos não significa tomar partido nas velhas e novas disputas, mas busca, sim, elucidar seus rastros. Nesse sentido, nosso procedimento será o de trabalhar o Caso Panther não apenas como objeto de interesse histórico, mas também historiográfico, cuja crítica nos permite repensar os termos e sentidos da relação entre os Estados Unidos e o Brasil. Nesse intuito, retomaremos nosso trabalho a partir do diálogo entre Burns e a narrativa de Álvaro Lins.

\section{A ideia da clivagem e o topos da continuidade}

No diálogo com Álvaro Lins, Burns construiu um raciocínio divergente do topos da continuidade no qual o Caso Panther é o evento que permite encadear uma representação da clivagem entre a velha e a nova política externa brasileira. A narrativa do incidente permite demonstrar que a relação com os Estados Unidos está inserida numa ordem de sentidos diferente, instruída por Rio Branco e Joaquim Nabuco. Como já apontamos anteriormente, a narrativa de Burns difere de Álvaro Lins por buscar distinguir mais o papel de Nabuco e elidir parte do sentido da atuação de Rio Branco. Note-se, como dado novo, que Burns também deixou de incluir uma compreensão que ele, muito provavelmente, já havia chegado: o encontro de Rio Branco com o embaixador alemão antecedeu o telegrama para Nabuco.

$\mathrm{Na}$ sua narrativa, Álvaro Lins fez a inversão na ordem da trama histórica de modo a endossar o argumento nacionalista. Observe-se que a expressão elidida por Burns - "Depois aconteça o que acontecer" - forma um par semântico quase perfeito com a frase que Álvaro Lins recortou do diário de Rio Branco: "Pois que seja uma guerra, Excelência, se isto desgraçadamente for necessário”. Entretanto, se Burns reordenasse a ordem dos eventos terminaria ressignificando o argumento nacionalista, que, como sabemos, era operado por José Honório Rodrigues.

Além disso, para Burns não interessava ressaltar o estilo da mensagem nem a excepcionalidade do seu conteúdo, mas a receptividade e a pronta resposta do governo estadunidense à notícia do incidente com a Panther. Em sua construção, o anúncio da visita de Root ao Brasil soma-se ao endosso dos Estados Unidos à postura brasileira no incidente, para desencadear uma escalada das simpatias no Brasil em direção à "aliança não escrita". Importa, sobretudo, fazermos notar a força e influência dessa construção, pois sua lógica foi corroborada por Moniz 
Bandeira, mesmo que a partir de outro olhar. No livro Presença dos Estados Unidos no Brasil, o autor conclui que a visita de Root se encerra com um "formidável êxito de propaganda" que permite a cristalização da "solidariedade e comunhão de sentimentos" dos representantes das elites oligárquicas com os Estados Unidos (1978, 173).

Por conseguinte, pode-se entender que a quebra do topos da continuidade permitiu juntar diferentes interesses num só raciocínio e mesmo agrupar esses investimentos numa nova composição. A clivagem da política externa é um constructo historiográfico em que a relação com os Estados Unidos passa a ser compreendida no bojo de uma nova ordem de sentidos, representada ora na figura da "aliança não escrita" ora pela ideia da dependência ou da colonização.

\section{A clivagem como herança?}

Como a lógica da 'nova ordem de sentidos' foi desenvolvida por meio de análises centradas na atuação brasileira, será que uma aproximação diferente deixaria entrever outra compreensão? Nesse caso, se nos valermos da atuação de Elihu Root como chave de leitura, podemos observar que sua viagem à América do Sul não se restringiu ao Brasil, mas ainda foi estendida para outros países, a saber, Uruguai, Argentina, Chile, Peru, Panamá, Colômbia, e só por falta de tempo não incluiu o Paraguai, a Bolívia e o Equador (BACON, 1917, xiii-xiv).

Nos discursos proferidos neste período, Elihu Root trabalhava a ideia de que uma transformação excepcional ocorria tanto nos Estados Unidos quanto na América do Sul, cujos termos ele definia na seguinte reflexão: nos Estados Unidos se acumulara, pela primeira vez, "um superavit de capital além do requerido para o desenvolvimento interno", enquanto na América do Sul "o progresso do desenvolvimento político estava levando o continente vizinho [...] para fora do estágio do militarismo e para dentro do estágio do industrialismo" (ROOT, 1917b, 246-247).

Abria-se, por conseguinte, uma janela de oportunidade para o comércio, para a expansão industrial e para a liderança estadunidense, urgindo, consequentemente, reconhecer e aproveitar a complementaridade de duas dinâmicas convergentes, a dos Estados Unidos e a da América do Sul, em proveito dos propósitos de uma estratégia global.

No Rio de Janeiro, Root assinalou que essa excepcionalidade poderia afirmarse como um "movimento continental" visando ao aumento da civilização, a ser materializado por meio do "intercâmbio e assistência mútua entre as repúblicas Americanas" e no respeito comum aos princípios democráticos. O progresso material era o fim último de uma opção conjunta que, pelo lado dos Estados Unidos, não aspirava a ganhos territoriais e ainda prometia preservar o continente dos efeitos das perturbações que já se avizinhavam na Europa. A liderança estadunidense sobre a comunidade americana significava, em resumo: "segurança e prosperidade, 
produção e comércio, riqueza, conhecimento, as artes e a felicidade para todos" (ROOT, 1917a, 10-11).

Observe-se que Root evocava todo um imaginário da colonização e da intervenção europeia, no qual ainda se evidenciava o fosso que separava os países periféricos das potências industrializadas. A cooperação pan-americana era propalada então como um compromisso assumido pela nação mais privilegiada junto às suas irmãs menores, em direção da igualdade, da liberdade e da prosperidade material. Nos enunciados de Root o incidente da Panther era um termo oculto, que por não necessitar ser explicitado em seu tempo, deixou de figurar na maioria das construções posteriores.

\section{A Panther no imaginário estadunidense}

Todos os textos que trabalharam o Caso Panther, de uma maneira ou de outra, procuraram mostrar que a real importância do incidente residiu em sua significação, que demonstrava a fragilidade da posição do Brasil no contexto internacional, pressionado pela Alemanha, pelos Estados Unidos ou pelas duas potências ao mesmo tempo. Algumas explicações ressaltaram ainda a importância do "perigo alemão" para a opinião pública da época, notando que Rio Branco não se impressionava com esse problema, e que o tema era parte da propaganda antigermânica divulgada pelos jornais brasileiros.

Em nossa aproximação, queremos observar que, muito antes do incidente, a Panther já ocupava lugar destacado no imaginário estadunidense como o símbolo da ameaça germânica aos Estados Unidos, ao ponto, por exemplo, de o jornal The New York Times ter registrado suas façanhas 81 vezes apenas entre o final de 1901 e o início de 1906, até mesmo destacando-a em editoriais e notícias de primeira página. Essa pertinência da Panther ao imaginário estadunidense possibilitaria repensar, dentre outras coisas, o episódio que causou tantos dissabores a Joaquim Nabuco, assim como a fala de Rio Branco no encontro com o embaixador alemão.

Sabemos por meio de pesquisas recentes que a presença naval alemã no Caribe fazia parte de uma ampla estratégia alemã para o continente americano. Nesse sentido, a Panther participou de várias missões na área e foi um dos barcos de guerra que no final de 1904 e início de 1905 participou do cruzeiro que passou por 52 portos e pelo menos 9 países do Caribe, numa missão que visava a demonstrar a força da presença alemã na região.

A Panther foi lançada ao mar em 1901 como parte do plano de construir barcos capazes de operar tanto no litoral quanto no interior dos continentes, de modo a poder estender a capacidade de operação de suas forças armadas e a influência da política externa germânica. Para melhor exercer essa função, sua oficialidade foi treinada nos usos culturais e na compreensão dos sistemas políticos estrangeiros, formando uma elite capaz de atuar com relativa autonomia em relação ao comando das relaçóes exteriores da Alemanha (WIECHMANN, 2000). 
Em 1903, por exemplo, quando enviada para reparos técnicos no Canadá, a Panther visitou vários portos daquele país fazendo uma política de relações públicas que impressionou vivamente a população local. Seus oficiais e marinheiros participaram então de regatas e apresentações musicais com sua banda, até mesmo sendo convidados para animar eventos locais (BASSLER, 2006, 117-118). Já em 1906, os oficiais da Panther aproveitaram a passagem pelos Estados Unidos e Canadá para cartografar e fotografar os portos e possíveis locais de desembarque naqueles países, bem como os pontos frágeis de seu sistema de cabos submarinos, informações estas que teriam sido de extrema utilidade para os ataques dos submersíveis alemães durante a Primeira Guerra (HADLEY, 2004, 165-166).

Contudo, seria por conta de outras atividades que a Panther passaria a representar o caráter da política alemã. Em 1902 a Panther interviu na guerra civil haitiana tomando partido da situação e afundando o principal barco daquele país, o Crête-à-Pierrot, então sob o comando de um almirante rebelde. Segundo o The New York Times, o Departamento de Estado teria julgado que a Doutrina Monroe não teria sido violada, uma vez que ela não deveria ser estendida ao ponto de proteger um comandante rebelde num país estrangeiro e que o episódio poderia até ser benéfico, prevenindo os atos contra o comércio costumeiramente praticados durante as instabilidades políticas da América Central e do Sul. ${ }^{2}$ Apesar disso, citando a repercussão internacional do incidente, o mesmo jornal notava que a admissão de limitações à Doutrina Monroe abria precedente perigoso, sendo "impossível deixar de perceber que algum incidente similar no futuro poderia atiçar uma fagulha na bucha do canhão da Doutrina Monroe", mesmo porque "o monroísmo conforme explicitado pelos homens de estado era uma coisa; as susceptibilidades do povo americano eram outra". ${ }^{3}$ Ainda assim, o The New York Times defendeu em editorial a posição do seu governo, comparando a atividade da Panther no Haiti com a intervenção estadunidense no Brasil durante a Revolta da Armada, julgando que em ambos os casos a ação contra os revoltosos fora justificada pela ameaça que representavam ao comércio internacional. ${ }^{4}$

Contudo, pode-se perceber uma transformação nas posições assumidas pelo jornal a partir do final de setembro de 1902, quando, citando um editorial do periódico inglês The Daily Telegraph, noticia que a Inglaterra e a Alemanha passariam a cooperar na América em torno do princípio da liberdade de comércio conforme definido pelo Tratado de Berlim de 1878, "buscando pôr fim a um estado de coisas que escandalizavam a moderna civilização e envergonhavam a cada país responsável pelo Tratado de Berlim". ${ }^{5}$ Esta compreensão de que um

\footnotetext{
2 "German act in Haiti perhaps injustified". The New York Times (NYT), 9 de setembro de 1902.

3 “Think Germany has set a dangerous precedent". NYT, 9 de setembro de 1902.

4 "The status of Haitian rebels". NYT, 10 de setembro de 1902.

5 NYT, 23 de setembro de 1902.
} 
princípio empregado na partilha da África estava sendo transposto para a América tornar-se-ia ainda mais premente nos Estados Unidos com a intervenção anglogermânica na Venezuela em 1902-1903, e especialmente quando a Panther e o barco inglês Fantome forçaram a barra do rio Orinoco, penetrando no território daquele país. Envolvidos no problema da secessão do Panamá, os Estados Unidos pouco mais fizeram do que condenar as atividades destinadas a cobrar pela força as dívidas venezuelanas, que incluíram o apresamento de barcos, o desembarque de tropas e o bloqueio dos seus principais portos. O bombardeamento do Forte de San Carlos, uma das ações levadas a cabo pelo esquadrão alemão comandado pela Panther, provocaria o editorial intitulado The German Way [O Estilo Alemão], no qual se enfatizava que aquela atitude constituía uma afronta ao governo estadunidense que tentava então negociar uma solução para o conflito, sintetizando a rudeza que caracterizava o modo de proceder da Alemanha a qual motivava a "renovação da agitação antigermânica nos Estados Unidos". ${ }^{6}$ A partir desse editorial a Panther começaria a ser lembrada enquanto uma representação do "estilo alemão", lembrando-se que era o barco que havia bombardeado o Forte de San Carlos e afundado o Crête-à-Pierrot, recebendo por isto o cumprimento do próprio Imperador: "Well done, Panther" [Bem feito, Panther].

Em outro editorial ficaria mais explícita a frustração dos que esperavam uma manifestação do governo contra o "estilo alemão": "quando ocasiōes como estas acontecerem no futuro, e elas vão acontecer, nós deveremos estar advertidos pela presente experiência", e se os alemães ou outra potência estrangeira "estiver pensando em negar o nosso direito de receber completas informaçôes de seus propósitos", deverá antes estimar "se a receita vale os custos da coleta"?

Depois, nos anos de 1903 e 1904, outros atritos menores com a Alemanha, dessa vez em Santo Domingos e no Haiti, também seriam referidos a partir de sua remissão à representação que a Panther evocava: "Bem feito, Panther" era a frase sempre repetida, se reclamando uma atuação mais convincente do governo estadunidense de modo a evitar a repetição do acontecido na Venezuela.

Por conseguinte, nossa compreensão do envolvimento dos Estados Unidos no incidente do Brasil é que este se desenvolve de reflexões anteriores, que levaram seu governo a buscar com celeridade obter satisfaçōes da Alemanha. Note-se que o editorial do The New York Times sobre o incidente no Brasil repete a linha e o estilo dos editoriais precedentes e termina, ademais, com a indefectível frase: "Bem feito, Panther". Isso nos leva a crer que sua contundência, ao lembrar que os Estados Unidos tinha ido à guerra com a Inglaterra em 1815 por conta de questão semelhante, pouco tinha a ver com os supostos esforços de Nabuco no sentido de provocar "reações monroístas", mas com a própria dinâmica da

6 "The German Way". NYT, 23 de janeiro de 1903.

7 "German explanations". NYT, 26 de janeiro de 1903. 
política externa estadunidense que levava em conta os insucessos anteriores e a suscetibilidade da sua opinião pública. Nesse mesmo sentido, pode-se compreender que a ida de Nabuco à Secretaria de Estado não é o verdadeiro denominador da atuação estadunidense, o que isentaria o embaixador da acusação de incitamento da intervenção estadunidense - provavelmente, a intervenção ocorreria de qualquer modo.

Ainda, havemos de considerar que o imaginário estadunidense era partilhado no resto do continente, o que permitiria explicar a excitação de Joaquim Nabuco e o posicionamento de Rio Branco no episódio. Decerto, foi o acerto anglo-germânico em torno dos princípios expressos no Tratado de Berlim que levou Joaquim Nabuco a escrever sobre o receio de que as "noçôes sugeridas pela partilha africana se possam aplicar à América" (NABUCO, 1903) ou que o "Direito Internacional Africano" (NABUCO apud BUENO, 1995, 69) fosse transposto para cá.

\section{A amizade alemã e a balança de poder}

Será que poderíamos trabalhar a ideia da continuidade também como um constructo historiográfico apontando sua lógica e depois trazer elementos novos para sua compreensão?

Analisando seu texto fundador, O Brasil, os Estados Unidos e o Monroísmo, escrito logo após o Caso Panther e antes da visita de Elihu Root, podemos notar que Rio Branco justifica a aproximação com os Estados Unidos a partir de uma enumeração de vários episódios que demonstrariam a continuidade de uma política desde antes da Independência. Nessa operação, Rio Branco seleciona documentos que demonstrariam a antiguidade da amizade entre os dois países, visando a atingir com esse argumento uma audiência específica, a dos seus críticos, que fundamentavam suas análises na demonstração de que as iniciativas de Rio Branco discrepavam dos fundamentos da política externa do Império.

Contudo, pode-se notar, pela análise do texto, que o argumento da antiguidade não basta para sensibilizar essa audiência: Rio Branco procura selecionar e grifar passagens que dizem respeito às impressóes causadas pelo contexto imediato, que não inclui apenas o Caso Panther, mas também as dissensōes com a Argentina e o Peru. Nesse sentido, os trechos destacados por Rio Branco são aqueles que dizem respeito à formulação de uma liga ou aliança ofensiva e defensiva com os Estados Unidos e é no bojo dessa lógica que ele explica a adesão precoce do Brasil à Doutrina Monroe.

$\mathrm{O}$ alcance desse argumento pode ser mais bem compreendido se recorrermos à análise da mentalidade das elites letradas do período e notarmos a grande disseminação na época de um saber afinado com a ideologia imperialista, que propunha um raciocínio sobre o Estado baseado na afirmação da importância do território e na balança de poder. Rio Branco era mesmo especialmente suscetível a esse tipo de raciocínio, uma vez que havia servido nos Estados Unidos e na 
Alemanha durante o período da maior divulgação e penetração das doutrinas baseadas no pensamento de Alfred Thayer Mahan. ${ }^{8}$

Ao mesmo tempo, podemos notar que esse discurso e seus enunciados podiam ser aproximados e assemelhados a um saber e um pensamento sobre o espaço constituído no Império e que este era entendido como tendo sido essencial para a manutenção do corpus da Nação (PEIXOTO, 2005). Se essa era a intenção de Rio Branco, poucas evidências sobraram para sua defesa, mas essas ainda nos permitem aventar que, se a aproximação com os Estados Unidos não era apenas um objetivo transitório e não permanente, dificilmente também poderia ser considerada como um alinhamento ou uma aliança estreita.

Pouco antes do incidente da Panther, em março de 1905, Rio Branco havia conseguido por intervenção direta do Imperador Guilherme II, que o Exército alemão admitisse oficiais brasileiros em suas fileiras. Coincidentemente, as condições do acordo estipulavam que, sete meses depois, no auge do incidente com a Panther, fosse necessário cuidar da oficialização e da renovação do estágio do primeiro grupo de militares. ${ }^{9}$ Havia, além disso, três outros interesses específicos: a compra de armas, a vinda da Missão Militar Alemã e o enorme intercâmbio comercial com a Alemanha que operavam no sentido de que o Caso Panther não desarticulasse as relações entre os dois países. Note-se que mesmo depois do incidente, Rio Branco continuou buscando esses objetivos e que em 1908 o expresidente Rodrigues Alves e o Marechal Hermes da Fonseca visitaram a Alemanha com sua estadia custeada pelos dois maiores fabricantes de armas daquele país, a Krupp e a Mauser. ${ }^{10}$

Alfred von Tirpitz, o todo-poderoso chefe do Almirantado alemão, sempre considerou o incidente como algo banal, "uma tempestade num copo d'água", ${ }^{11}$ e os diplomatas alemães dedicaram os maiores esforços, durante e depois do incidente, para evitar prejuízos, cuidando, por exemplo, de evitar que os barcos de guerra alemães parassem nos pequenos portos do sul do Brasil. ${ }^{12}$ Além disso, Rio Branco conhecia o roteiro que a Panther cumpriria no Brasil e, ademais, tinha obtido junto à Marinha permissão para que realizasse exercícios de tiro na sua passagem pelo Rio de Janeiro. O Ministro sabia também que, dois meses antes, a Panther já tinha ocasionado outro incidente na capital da Paraíba (GUEDES, 2002, 314-315).

Foi a grande imprensa que criou o clima de enfrentamento com a Alemanha, fazendo com que esse clima transbordasse para a Câmara, onde a oposição passou

8 Alfred Thayer Mahan (1840-1914), oficial de Marinha dos Estados Unidos, é hoje considerado por muitos como o iniciador do pensamento geopolítico.

9 AHI 302 - Pasta 203.3.1 - Legação em Berlim para o Ministério das Relações Exteriores, 31 de dezembro de 1905.

10 AHI 352 - Pasta 203.3.1 - Tel. da Legação para o Ministério das Relaçôes Exteriores, 16 de junho de 1908.

11 Alfred von Tirpitz para o Almirantado alemão, 17 de setembro de 1906. Apud Wiechmann, 2000, 415.

12 Tel. de Treutler, representante alemão no Brasil para Bülow, Secretário de Estado do Império alemão, $1^{\circ}$ de setembro de 1906. Apud Wiechmann, 2000, 416. 
a protestar duramente contra o suposto atentado alemão à soberania nacional. ${ }^{13}$ Aliás, Rio Branco já havia dito ao próprio Guilherme II, em 1901, que a imprensa do Brasil era influenciada contra a Alemanha pelos interesses estadunidenses, ${ }^{14}$ impressão que seria repetida depois da solução do incidente. ${ }^{15}$

A crise diplomática terminou no dia 6 de janeiro de 1906, quando foi divulgada uma declaração aprovada pelo Imperador Guilherme II e assinada conjuntamente pelo Barão de Richthofen, Chanceler alemão, e pelo Príncipe de Bülow, Secretário de Estado do Império. Na declaração, expressava-se o vivo pesar pelo que o governo brasileiro havia passado, apontando o apreço pela amizade com o Brasil e o desejo de fortalecer os laços já existentes. Dizia ainda que os inquéritos alemães comprovaram que seus agentes haviam ultrapassado os limites do encargo recebido e que por isso seriam submetidos à justiça militar de seu país, mas frisava que estes apenas haviam procedido a um uso universalmente seguido pelas marinhas de guerra, que era o de buscar seus desertores.

\section{Entre as dinâmicas do regresso e do progresso}

Ainda que a declaração da Alemanha fosse de encontro a tudo aquilo que fora pleiteado pela imprensa, os artigos e notícias denunciando a "prepotência alemã" e o "perigo germânico" continuaram a ser veiculados pela imprensa durante todo o ano de 1906. Foi nesse período que os jornais construíram a narrativa de que a agressão alemã fora motivada por um plano secreto do Estado-Maior alemão, visando a anexar o sul do Brasil com o apoio dos colonos alemães. No caso, Rio Branco teria facilitado uma futura anexação na medida em que se acovardou com a exibição imperialista, não cortando relações com a Alemanha nem insistindo numa punição exemplar para o comandante da Panther.

Esse tema tornar-se-ia, daí em diante, lugar-comum na cultura política, impressionando a produção das ideias sobre a nação e a identidade que seriam retomadas, inclusive, no ambiente especial do final da década de 1950. Seria no contexto das disputas da Guerra Fria que a ideia da continuidade seria retomada por Álvaro Lins, que reelaboraria o texto de Rio Branco a partir do argumento de que sua análise da transformação da balança de poder mundial e hemisférica fora perfeita. Contudo, para Lins esses condicionantes não seriam suficientes para explicar por que a ênfase original de Rio Branco numa liga ou aliança ofensiva e defensiva com os Estados Unidos foi reelaborada numa construção que privilegia suas observaçôes a respeito do monroísmo. Para isso, seria necessário entendermos que a aproximação com os Estados Unidos foi trabalhada a partir de uma ordem

13 Anais da Câmara dos Deputados, dezembro de 1905, pp. 160-161.

14 AHI 364 Lata 854 Maço 1 Pasta 2 Tel. de Rio Branco, representante do Brasil em Berlim, para o Ministro das Relaçōes Exteriores.

15 AHI 327 203.3.1 Tel. de Rio Branco para o Ministro Brasileiro em Berlim, 9 de janeiro de 1906. 
diferente: esta teria se dado numa colaboração especial, que destacou nosso país das demais nações sul-americanas, uma vez que o Brasil, por meio da herança do saber do Império, transformara mesmo a essência da Doutrina de Monroe, que integrava "no seu corpo, em formação ainda naquela época, princípios e ideias da política externa brasileira” (LINS, 1965, 337).

Note-se que a leitura de Álvaro Lins se faz para uma audiência em que a geopolítica faz sentido, acreditada enquanto Ciência e ensinada em universidades, academias militares e no Instituto Rio Branco. Ainda, a interpretação de Lins se insere no contexto interno, que implicava a necessidade de ter de explicitar o alinhamento com os Estados Unidos e a luta contra a subversão comunista. Nesse ponto o retorno da tradição não se daria no seu encontro com a política externa, mas também na política interna - Lins entendia que o verdadeiro legado de Rio Branco era a possibilidade de encontro do passado com um projeto capaz de imprimir um futuro próspero para a Nação:

Enfrentando a ironia ou a cólera dos livres-pensadores do jacobinismo republicano, o presidente Rodrigues Alves, na sua primeira mensagem ao Congresso, invocava o nome de Deus. Era a primeira vez que, na República, o chefe de Estado fazia apelo à Providência Divina em documento dessa espécie. Isto representava [...] um sinal dos novos tempos, indicava a vitória do espírito tradicional através da "república dos conselheiros" (LINS, 1965, 340).

Foi justamente contra esse constructo que junta as dinâmicas do regresso e do progresso, que se lançaram não apenas releituras da história da política externa, mas, sobretudo, visóes sobre o espaço e a identidade nacional que procuravam repelir aquilo que acusavam de atraso. Ao final, Rio Branco foi ressignificado a partir de posições que dificilmente endossaria, já que ele mesmo estava empenhado numa operação que colava o passado às possibilidades que o presente oferecia.

\section{Referências bibliográficas}

Fontes primárias:

Arquivo Histórico do Itamaraty - Rio de Janeiro (AHI).

The New York Times (NYT).

Anais do Congresso Nacional.

Fontes secundárias:

BACON, Robert \& SCOTT, James Brown (Org.). Latin America and the United States-Addresses by Elihu Root. Cambridge: Harvard University Press, 1917.

BANDEIRA, Luiz Alberto Dias Lima de Vianna Moniz. O milagre alemão e o desenvolvimento do Brasil. São Paulo: Editora Ensaio, 1994.

BANDEIRA, Luiz Alberto Dias Lima de Vianna Moniz. Presença dos Estados Unidos no Brasil (Dois séculos de história). Rio de Janeiro: Civilização Brasileira, 1978. 2a Edição. 
BASSLER, Gerhard P. Vikings to U-Boats: the German experience in Newfoundland and Labrador. Quebec: McGills-Queen's University Press, 2006.

BUENO, Clodoaldo. (1995) A competição alemã no Brasil no início do Século XX: o incidente da Panther. Revista Brasileira de Política Internacional. Vol. 38, № 1, 1995.

BUENO, Clodoaldo. A competição alemã no Brasil no início do Século XX: o incidente da Panther. Revista Brasileira de Politica Internacional Vol. 38, No 1, 1995.

BURNS, E. Bradford. The Unwritten Alliance: Rio-Branco and Brazilian-American Relations. New York: Columbia University Press, 1966.

CALMON, Pedro. História do Brasil (Volume 6). Rio de Janeiro: José Olympio, 1959.

CARVAlHO, Carlos Delgado de. História Diplomática do Brasil. São Paulo: Companhia Editora Nacional, 1959.

CERVO, Amado Luiz \& BUENO, Clodoaldo. História da Política Exterior do Brasil. São Paulo: Editora Ática, 1992.

DERRIDA, Jacques. Gramatologia. São Paulo: Perspectiva, 2001.

DORATIOTO, Francisco Fernando Monteoliva. A política platina do Barão do Rio Branco. Revista Brasileira de Política Internacional. Vol. 43, No 2, 2000.

GUEDES, Max Justo. O barão do Rio Branco e a modernização da defesa. In Rio Branco, a América do Sul e a modernização do Brasil. Rio de Janeiro: EMC, 2002.

GUIMARÃES, Manoel Luiz Salgado. Historiografia e cultura histórica: notas para debate. Ágora, Vol. 11, No 1, 2005, p. 31-48.

HADLEY, Michel L. "Wartime German hydrography in Canadian waters" in Charting northern waters: essays for the centenary of the Canadian hydrographic service. William Glover (Ed.). Quebec: McGills-Queen's University Press, 2004.

JOFFILY, José. O Caso Panther. Rio de Janeiro: Paz e Terra Editora, 1988.

LINS, Álvaro. Rio Branco (O Barão Do Rio Branco): Biografia Pessoal e História Política. São Paulo: Companhia Editora Nacional, 1965, 2a Edição revista.

NABUCO, Joaquim. O direito do Brasil: primeira memória apresentada em Roma a 27 de fevereiro de 1903. Rio de Janeiro: A. Lahure, 1903.

OLIVEIRA, José Manoel Cardoso. Actos diplomáticos do Brasil. Tomo II. Brasília: Senado Federal, 1997.

PEIXOTO, Renato Amado. A máscara da Medusa: a construção do espaço nacional brasileiro através das corografias e da cartografia no século XIX. Tese de doutorado em História, Universidade Federal do Rio de Janeiro, Rio de Janeiro, 2005.

PEIXOTO, Renato Amado. Terra Sólida: A influência da geopolitica brasileira e da Escola Superior de Guerra na politica externa do governo Castello Branco. Dissertação de Mestrado em História, Universidade Estadual do Rio de Janeiro. Rio de Janeiro, 2000.

RIO BRANCO. O Brasil, os Estados Unidos e o Monroísmo. Revista do Instituto Histórico e Geográfico Brasileiro. Vol. 178. Janeiro/Março 1943, p. 167-188.

RODRIGUES, José Honório \& Seitenfus, Ricardo A. S. Uma História Diplomática Do Brasil. Rio de Janeiro: Civilização Brasileira, 1995. 
RODRIGUES, José Honório. Interesse Nacional e Política Externa. Rio de Janeiro: Editora Civilização Brasileira S.A., 1966.

ROOT, Elihu. At the Third Conference of the American Republics (31/07/1906) In. BACON, Robert \& SCOTT, James Brown (Org.). Latin America and the United States - Addresses by Elihu Root. Cambridge: Harvard University Press, 1917, p. 3-13.

ROOT, Elihu. How to develop South American commerce' (20/11/1906) In. BACON, Robert \& SCOTT, James Brown (Org.). Latin America and the United States - Addresses by Elihu Root. Cambridge: Harvard University Press, 1917, p. 245-268.

VIANA FILHO, LUIZ. A Vida do Barão do Rio Branco. Rio de Janeiro: José Olympio Editora, 1959.

VIANNA, Hélio. História Diplomática do Brasil. São Paulo: Edições Melhoramentos, 1958.

WIECHMANN, Gerhard. Die preußisch-deutsche Marine in Lateinamerika 1866-1914: eine Studie deutscher Kanonenbootpolitik. Dissertação de Mestrado em História. Universidade de Olderburg. Oldenburg, 2000.

Recebido em 14 de maio de 2010 Aprovado em 11 de janeiro de 2011

\section{Resumo}

O Caso Panther foi um incidente que envolveu o Brasil e a Alemanha e que teve grande repercussão internacional em sua época, ficando marcado na história da política externa brasileira enquanto um episódio de agressão imperialista contra o Brasil e como o momento que marca a aproximação entre nosso país e os Estados Unidos. Acreditamos, porém, que uma rediscussão do Caso Panther permita um novo exame das dinâmicas do Imperialismo a partir de um olhar periférico, bem como uma outra compreensão das ideias acerca da nação que imprimiram suas marcas no pensamento de Rio Branco.

Palavras-chave: política externa brasileira; Caso Panther; imperialismo; Rio Branco.

\section{Abstract}

The Panther Affair was an incident involving Brazil and Germany that had great international influence in its day, being marked in the history of Brazilian foreign policy as an episode of imperialist aggression against Brazil and as the moment that marks a rapprochement between Brazil and the United States. We believe, however, that a renewed discussion of the Panther Affair allows a fresh examination of the dynamics of imperialism from a peripheral look and a different understanding of other ideas about the nation that left its mark on the ideas of Rio Branco on foreign policy.

Keywords: Brazilian foreign policy; Panther Affair; imperialism; Rio Branco. 